\title{
Best Learning Practices from an Online Law Student: An Informal Case Study
}

\author{
Barrett Vaughan, Ph.D. \\ P.O. Box 230221 \\ Montgomery \\ Alabama U.S.A
}

\begin{abstract}
An illustrative case study, involving the experiences of one student, examined the attempts to enhance the learning process of online legal education. The primary technique used to reinforce distance learning was repetitively listening to free or low-cost bar review audio lectures from bar review companies. There were three aspects observed from this "immersive strategy": an increased frequency of exposure to legal education materials; a reinforced learning from various sources through repetition, and; an increased familiarity with the material. It was concluded that this strategy promoted this student's confidence.
\end{abstract}

Keywords: Online law school, Auditory learning, Bar review, Smartphone

\section{Introduction (“Law School, Online?")}

"If you wish to be a lawyer, attach no consequence to the place you are in, or the person you are with; but get books, sit down anywhere, and go to reading for yourself. That will make a lawyer of you quicker than any other way." Abraham Lincoln ${ }^{1}$ First, let me agree with you, the study of law is best accomplished in a classroom, not by correspondence or through distance. Empirical evidence, most notably Bar passage rates, clearly shows this. Furthermore, your own experiences in legal education likely bear witness to this being most reasonable. However, for those of you reading who will resist the leanings to dismiss the concept of online law school and anything related to it out of hand, I would like to share with you my experiences in navigating through my first year of law school online, and the tools I utilized to do so, to some extent, successfully. There may be the minuscule but distinct possibility that some part of this may be of use to you or to your students.

\section{Background ("Law School, Online!")}

I would like to begin by saying that the California Bar's variance of permitting admission via a four-year correspondence or online program of study is mischaracterized at best. I have come to understand that under the established system, it is more accurate to state that there is indeed similarly three years of schooling. However, it is preceded by a full calendar year of preparation for a qualifying exam. The exam is, as you may know, the California First Year Law Students Examination or FYLSX. It is an abbreviated, i.e., one-day, version of their Bar Exam, also known as the "Baby Bar," that tests contracts, criminal law, and torts by essays and multiple-choice questions. Should a student not be successful in passing this exam, he or she will not be eligible to continue his or her studies. Period. Therefore, my conclusion is that the first year is more aptly described as preparation for admission to legal study. ${ }^{2}$ That being said, the question is, "How would an online student be able to address the missing components that brick-and-mortar schooling inherently offers?" That is, "How would a student still keep pace with learning and understanding in general, as measured by the Bar through the FYLSX and ultimately the Bar Exam?" I hope now to offer some ideas. Just to offer a bit of background, let us start with how California online law studies are structured. Studies in the first, or preparatory, year necessarily focus on content in three areas, contracts (formation, interpretation, damages, etc.,) criminal law (against property, persons, etc.,) and torts (intentional, negligence, strict liability, etc.,) in some order.

${ }^{1}$ The Collected Works of Abraham Lincoln edited by Roy P. Basler, Volume II, "Letter to William H. Grigsby" (August 3 , 1858), p. 535.

${ }^{2}$ There are those who view these online institutions with contempt, criticizing them as taking advantage of unfit students. I take heart in knowing that such a school, if there are any, can only do so for so long. They will ultimately have no students at all if they do not show the ability to prepare students for the FYLSX. The FYLSX and Bar passage rates are included in the enrollment agreement disclosures. 
The typical online delivery would be by lecture complemented by a variety of in-class and out-of-class individual or group exercises or sessions. Interaction is possible, but that similar to a classroom experience is not usually feasible (e.g., use of the Socratic Method.) As you would expect, the professors hold virtual "office hours," and can also respond to questions by email. The casebooks and other materials are likely similar to those employed nationally. Online students are required by the Bar to account for an average of eighteen (18) hours of class and study weekly over a continuous 48- to 52-week period. Otherwise, the emphasis on case briefing, the training on writing using IRAC format, the posing of hypothetical questions, etc., is likely similar.

\section{Problem ("How is online learning different?")}

There are, however, differences that have consequently and consistently manifested in lower Bar passage rates. In my estimation, the greatest difference, that is other than the virtual class lecture delivery and interaction, had to be the immersion of students in a vibrant, dynamic, (and "pressurized") learning environment. I drew this conclusion by process of elimination: the professors are experienced lawyers and graduates of top-tier brick-and-mortar schools (e.g., Berkeley), the casebooks are those that are commonly used, the courses cover the entire casebook, and the learning is guided by well-tested law outlines (i.e., Barbri.) On an individual student level, (i.e., not the class body as a whole), yet and still taking into account the qualifications and commitment of the student, the only aspect remaining was the environment.

So, how does a student take the initiative to simulate for himself or herself such an immersive learning environment? In my imagination, I see such an environment as a space where students are perpetually engaging in nothing but The Law, figuratively eating, breathing, talking, and sleeping it every day.

\section{Methods and Results ("What was my solution? How well did it work?")}

Here was my solution. For me, as an auditory learner, the most logical strategy to create such an environment was to listen to lectures and to make it possible to do so anytime and at any place. This is where technology comes in. The audio of my course lectures was available for download for use in a portable media player, i.e., a smartphone. ${ }^{3}$ Doing so allowed me to review, most anytime and in any place, the discussions from class.

However, a review of classroom proceedings, particularly when you were present (logged in) for class, ultimately has limited merit. In every three hours of "live" class (twice weekly), much of the audio is class instructions or "housekeeping," the silence between questions and responses (typing time plus video stream lag), the instructor's addressing of erroneous and correct responses, witty banter, etc. Though the content may be helpful at that time or the first time it was reviewed, it may not have much long-term instructional value in toto.

Thankfully, the same technology that made listening to class audio, a smartphone, offered other options. The bar review program that came with school enrollment, Barbri also included a smartphone 'app' with access to outlines, multiple choice questions, and full, three- to six-hour video and audio lectures on the 'black letter' law and applications in all first-year subjects. These lectures are, by contrast, succinct, comprehensive, and structured coverages of the doctrine. Though these lectures may have been recorded live, the setting was a bar review session, with a markedly different audience in terms of interaction, if any.

Listening to these lectures was extremely helpful, as they not only allowed me to review but also preview the course content. It also allowed me to appreciate the entirety of the doctrine and place what I was learning at the time in class in a broader context. For example, while I was just learning the intentional torts, I was building a mental framework of their relationship to negligence and strict liability. In addition, by the time I was assigned to read and brief the landmark cases in the casebook (e.g., Palsgraf,) I was already somewhat familiar with their holdings and broader implications.

Ultimately, the amount of bar review audio available from Barbri was exhausted between my regular forty-fiveminute commute to work, infrequent workouts on the treadmill at the gym, and wait time in line or offices. (Bluetooth headphones became a necessity.) So, I was led to seek out if there were other bar review audios or videos available. I learned about Kaplan PMBR, the main competitor of Barbri and their introductory and moderately priced '1L Edge' program (since then renamed 'First Year Success' program.) It similarly offered outlines, multiple-choice questions, and more video and audio lectures.

${ }^{3}$ Please note that as I refer to a "smartphone," I mean any technology that would allow the media playing functions necessary, such as a tablet, netbook, "smartwatch," etc. 
Now I could add these lectures to create a rotation, a 'playlist' of sorts, to cycle through. As a bonus, the resources offered by Kaplan PMBR were also available in an 'app' for use on my smartphone. Though the content of the two companies' lectures is certainly similar, the treatment and emphases were slightly, or in some instances markedly, different. Certainly, you understand that there is only one Bar Exam (well, about 50-plus versions of it,) and they are both the leaders at helping students nationwide pass it. The slight differences allowed me to have a fuller access and ultimately some broader understanding of the details (e.g., exceptions) within the doctrines. It also allowed me to be able to have a mental dialogue comparing and contrasting them, along with the course content to that point. It also allowed me to put the casebook rulings in an historical context with modern law. For example, the historical case law regarding injury to child trespassers, also known as the "attractive nuisance" doctrine in torts, required that the condition on the land actually draw, or "attract" the minor onto the land. Modernly, this element is not required. As to the quality of these lectures, they are given by professors from notable institutions of law. For Barbri, Professor Roger Schechter from George Washington University lectures on torts, Professor David Epstein of University of Richmond lectures on contracts, and Professor Joseph Thai from University of Oklahoma lectures on criminal law. For Kaplan PMBR, Professor Lawrence Levine of Pacific McGeorge School of Law and Robert Feinberg, PMBR founder, lecture on torts, Professors Wayne Barnes of Texas Wesleyan School of Law and Daniel W. Fessler of University of California, Davis lecture on contracts, and Professor Geoffrey Corn of South Texas College of Law and Robert Feinberg lecture on criminal law.

I later sought out and discovered other quality, free or low-cost bar preparation resources that included audio lectures, along with outlines, multiple choice questions, etc. For instance, Themis Bar Review, another competitor, offered, at no charge, a first-year program with video lectures, quizzes on the doctrine, and outlines, supported by an 'app.' An 'app' in the Google Play Store from Celebration Bar Review, 'Pocket MBE,' included sixty hours of streaming audio lectures along with outlines and multiple-choice questions for less than three dollars. As I discovered more audio lecture resources, I extended my 'playlist,' and became exposed to more voices and views on the substantive areas of the law. ${ }^{4}$

Of course, listening to lectures from even the greatest legal minds is no substitute for following the development of the doctrine through reading the significant cases in the casebook. However, towards a more immersive environment, technology again plays a role in this integral part of legal education. Most modern casebooks now have an electronic version, an "e-book," either in the Amazon Kindle format or the publisher's own online platform. These electronic versions typically permit searching, notes, and bookmarks. The availability of an electronic casebook made it possible for me to read anywhere at any time, on multiple devices, including my smartphone. The convenience of having an e-book ready at hand was particularly important in being able to 'digest' the significant volume of reading required. Personally, much of my reading took place late at night and early in the morning. Though for the traditional law student, an electronic book may merely be a commonplace convenience, however, for an online student, it may be a necessity for success. The schedule of the former student is virtually open time for reading and outlining, but for the latter student, who is typically pursuing the degree part-time, time available for study may be irregular and/or scattered throughout a week. For these reasons, an electronic book is a boon and contributes to the immersive learning environment.

The other critical resource was access to legal research tools. Along with Barbri, school enrollment included access to Westlaw. (I would assume that alternately other services such as Lexis/Nexis would be available to students at other schools.) Thankfully, the access to Westlaw included (surprise, surprise) a smartphone 'app,' linked to the student account. That is to say, what I searched or saved online by computer was also be accessible by smartphone. Having access to quality legal research tools from anywhere complemented the audio lectures and the electronic casebook. Being able to search and review the sections of the Model Penal Code, the Restatements, or the Uniform Commercial Code made studying, reviewing, and contemplating the case law deeper and richer. Therefore, armed with my smartphone, and being able to read my casebook, listen to great doctrinal lectures on an incrementally increasing playlist, and look up sections of the Restatements or UCC, I completed my first year.

${ }^{4}$ Eventually each of my three class playlists included around thirty hours of audio lectures. For example, in Torts, the playlist included four hours from Barbri, six hours from Kaplan PMBR, another five bonus hours from Kaplan PMBR, four hours from Themis, five hours from Celebration Bar Review, and five hours from Hugh Reed of Reed Bar Review--which was available at no cost from their website. 
Because online students are required to weekly log their hours of study (something that is easily done with the smartphone calendar 'app,') I soon began to note that the amount of time that I devoted to my studies weekly was at or above the Bar-required amount.

\section{Discussion ("Did it help?")}

Your question at this point may likely be, "So how did it help, and what was the final outcome." There are three aspects of the "immersion strategy" outlined above that I believe helped me. These aspects are an increased frequency of exposure to legal education materials, reinforced learning from various sources through repetition, and, an increased familiarity with the material, all of which promoted confidence. The first aspect, and possibly the most salient, is an increased frequency of exposure to legal education materials. I hesitate to state, "increased frequency of study," because some of you might not consider listening to audio lectures as actual 'study.' The main idea, however, is that with a non-traditional student, the periods of study and the periods between those sessions become longer and shorter, respectively. If I were to have waited to engage the course materials until a time where I could sit down with my casebook or in front of my computer, I would have had a lesser frequency of exposure to the materials, i.e., I would have "studied" less.

The second aspect is a greater reinforcement of learning through the repetition of the same content but from different sources. On this subject, several notable experts have contributed their wisdom. Zig Ziglar is quoted as saying, "Repetition is the mother of learning, the father of action, which makes it the architect of accomplishment." John Wooden, Hall of Fame basketball coach from UCLA is quoted as saying, "Repetition is the key to learning." Marvin Minsky, cognitive scientist and co-founder of the MIT Artificial Intelligence laboratory is quoted as saying, "You don't understand anything until you learn it more than one way." Essentially, the use of a variety of high quality legal educational resources, e.g., the audio lectures from the various Bar preparation courses, reinforced the learning from the class lectures. Also, because it was not a repetition of the same lecture, but of a number of different lectures on the same topic, there was a variety of educational techniques and approaches. Furthermore, it kept the listening to the lectures from becoming tedious.

The third aspect is increased familiarity with the material. My strategy with listening to the audio lectures was to listen, when I could, to the entire set of lectures in series starting at the beginning of the course. As stated earlier, this practice helped me build a framework for understanding and mentally organizing the class material. When I first began to listen to the series of lectures, I knew that there would unquestionably be some material that I would not be able to grasp yet. However, I knew that as soon as it was covered in the casebook and in my class, it would fall neatly into place. For me as a student, this takes away much of the trepidation associated with (seemingly most) law courses.

\section{Conclusion ("What was the outcome?")}

How the confidence was built was a cumulative outcome from these three aspects. First, the ability to study anywhere at any time keeps you on pace with your casebook reading and research. Listening to the lectures gives you insight into the topic, and, because there are multiple sources and repetition, this insight is broadened and reinforced. Further, being able to have a forward-looking approach to the class, far deeper than an examination of the syllabus, gives a "roadmap" to the learning. Having these three at hand, from this simulated "immersive learning environment," can build, as it did for me, confidence in one's ability to be successful in legal studies. Perhaps students in traditional brick-and-mortar institutions innately own this confidence; they know they will succeed. However, those for whom this experience of law school, particularly online, is a novel one, this confidence is paramount to progress and success.

Table1. Bar review resources used and web addresses.

Resource

Barbri

Kaplan (PMBR)

Themis Bar

Celebration Bar Review

Reed Bar Review

Pearce Bar Review

Emerson's Bar Review
Web address

barbri.com

kaptest.com/bar-exam

themisbar.com

celebrationbarreview.com

reedbarreview.com

passthebar.com

emersonsbarreview.com 